\title{
Microscopic Findings Subcategory
}

National Cancer Institute

\section{Source}

National Cancer Institute. Microscopic Findings Subcategory. NCI Thesaurus. Code

C117581.

A subdivision of microscopic findings data. 